\title{
Antioxidants: Friend or foe for tuberculosis patients
}

\author{
Rajasri Bhattacharyya1, Dibyajyoti Banerjee ${ }^{2 *}$ \\ ${ }^{1}$ Department of Biotechnology, Maharishi Markandeshwar University, Mullana, Ambala, India \\ ${ }^{2}$ Department of Experimental Medicine and Biotechnology, Postgraduate Institute of Medical Education and Research, Chandigarh, \\ India \\ Email: *dibyajyoti5200@yahoo.co.in
}

Received 22 August 2013; revised 22 September 2013; accepted 15 October 2013

Copyright (C) 2013 Rajasri Bhattacharyya, Dibyajyoti Banerjee. This is an open access article distributed under the Creative Commons Attribution License, which permits unrestricted use, distribution, and reproduction in any medium, provided the original work is properly cited.

\begin{abstract}
Respiratory burst induced bacteria killing by oxidants are important mechanism of host defence. However, it is impaired in tuberculosis due to inhibition of respiratory burst by Mycobacterial factors. Antioxidants are compounds that cause chelation of reactive oxygen species. So, antioxidants are expected to play a negative role in the management of active tuberculosis. But, oxidative stress is a proved fact that invariably happens in tuberculosis patients which is known to cause immunosuppression. Immunosuppression in turn is expected to augment tuberculosis. Hence, antioxidant supplementation is expected to benefit tuberculosis patients by minimising oxidative stress induced immunosuppression. Therefore, the role of antioxidants in tuberculosis appears to be paradoxical and urgent. Understanding of the role of antioxidant supplementation in tuberculosis is warranted. It is in this context that we have reviewed the recent literature and addressed the problem for its solution.
\end{abstract}

Keywords: Tuberculosis; Antioxidants; Reactive Oxygen Species; Clinical Trial; Mycobacterial tuberculosis

\section{INTRODUCTION}

Antioxidants are among the most popular health-protecting products, sold worldwide without prescription. At the present moment, there is majority opinion that antioxidants are good for human health but very recently some researchers are in the opinion that it may not be good for human health universally [1].

In case of infections intracellular generation of ROS/ RNS plays an important role in pathogen clearance.

*Corresponding author.
Phagocytosis is the process by which all pathogens are engulfed by the macrophages. In the process of phagocytosis, a membrane bound vesicle is formed containing the pathogen. This membrane bound vesicle, is popularly known as phagosome. Phagosome generally contains various subunits of NADPH oxidase, the respiratory burst enzyme (that generates superoxide), iNOS (that generates peroxynitrite), and many other proteins that generally undergoes a maturation process by which internalized particles (such as bacteria and dead cells etc.) are trafficked into a series of increasingly acidified membrane-bound structures (endosomes, lysosomes), leading to particle degradation [2,3]. It is also now proved that if the phagosomal ROS is not produced or less produced the host becomes susceptible to intracellular infections. The classical example of the above statement is chronic granulomatous disease which is characterized by diminished capacity of intracellular ROS production leading to tuberculosis very often [4].

The role of extracellular antioxidants may be critical in functioning of intracellular ROS. It is expected that the available extracellular antioxidant will percolate inside the cell and neutralize the nascent ROS. In that case antioxidants should be harmful in the scenario of active infections. However, some antioxidants behave as prooxidants in specialized situations. Below an example is elaborated for explanation of the above mentioned fact.

$\alpha$-tocopherol ( $\alpha$-TC, Vitamin E) produces $\alpha$-tocopheroxyl radical when it reacts with reactive species such as peroxynitrite [5] or superoxide [6]. $\alpha$-TC radical is then recycled to $\alpha$-TC by other antioxidants such as ascorbic acid (Vitamin C) and glutathione [7-9]. As soon as ascorbic acid recycles Vitamin E, it is transformed to the ascorbyl radical, which has a lower reactivity than $\alpha$-TC radical [7]. $\alpha$-TC radical is also recycled to $\alpha$-TC by $\beta$-carotene $[9,10]$. So, for proper antioxidant effect Vitamin $\mathrm{E}$ should be administered with another antioxidant and excess amount of vitamin E may be pro-oxidant 
per se. Therefore, it is important to understand the role of vitamin $\mathrm{E}$ in various concentrations in presence and absence of other antioxidants, on the re-ox capacity of intracellular nascent ROS. Similar examples may be cited with all the commonly used antioxidants and the role of commonly used antioxidants in intracellular ROS production/function is unclear as on date. Such knowledge is important keeping in mind the prevalence of the infectious diseases and the consumption habit of antioxidants of public at large. In this article the same will be attempted to be reviewed in the context of tuberculosis.

\section{PHAGOSOMAL NICHE FOR Mycobacterium tuberculosis}

Mycobacterium tuberculosis is engulfed by host macrophages. It resides inside a stable phagosome which does not fuse with lysosome for effective bacterial killing. Such maturation arrest of phagosomes containing $M y$ cobacterium tuberculosis is thought due to defective recruitment of rab proteins in such phagosomes [11]. Mycobacterial factor like secreted acid phosphatase is also thought to be important for inhibition of phagolysosome biogenesis [12]. As a result the tuberculosis bacterium resides inside the phagosome without experiencing the adverse environment produced by lysosomal acid hydrolases. Moreover Mycobacterium containing phagosome recruits cellular iron into the phagosome which is utilized for bacterial sustenance [13]. The phagosome is supposed to posses subunits of NADPH oxidase, the key enzyme for respiratory burst which in turn is expected to generate superoxide. Further myeloperoxidase in phagosome is known to form hypohalites. Both superoxide and hypohalites are known agents that kill intraphagosomal parasites. Inducible nitric oxide synthase is also known to be recruited in phagosomes which generates peroxynitrite, the toxic free radical and mediates bacterial killing. However, Mycobacterial factors are known to inhibit the function of inducible nitric oxide synthase and NADPH oxidase and thus less oxidants are produced in Mycobacterium tuberculosis containing phagosome, making the phagosomal pathogen to stay inside a protective cover $[14,15]$.

\section{TUBERCULOSIS AND THE ANTIOXIDANT PARADOX}

Mycobacterium tuberculosis is an intracellular pathogen and currently infected more than one third of global population. Like all intracellular pathogens it resides successfully inside phagosome of macrophages. Мycobacterial factors inhibit phagosome maturation so that the intraphagosomal bacterium is not assaulted by lysosomal hydrolases [12]. Various bacterial antioxidants are also proved to counter phagosomal respiratory burst causing safe stay of the tuberculosis bacterium inside the phagosome [16-18]. In case of atypical Mycobacterium species bacterial antioxidants are thought to modulate host derived oxidative killing mechanisms [19]. In Mycobacterium species new antioxidant mechanisms that protect the bacterium from the phagosomal respiratory burst is an established phenomenon [20,21]. Even recombinant BCG over-expressed with superoxide dismutase A confers less protection for development of tuberculosis [22]. Pathogen derived antioxidant mediated escape from phagosomal oxidative burst is not unique for tuberculosis bacterium and proved to be true in other successful intracellular pathogen as well $[23,24]$. Host derived antioxidants are also recently proved to be beneficial for persistence of intracellular pathogens [25]. Therefore it is appearing that availability of antioxidants at the phagosome play a negative role for the host in cases of active tuberculosis infection.

On the other hand antioxidants like $\mathrm{N}$-acetyl cysteine is shown to inhibit growth of tuberculosis bacteria inside tubercular abscess [26]. Such observations are also confirmed with other antioxidants like manganese (II) mesotetrakis-(N-methylpyridinium-2-yl) porphyrin [27]. Further, glutathione is known to modulate the $\mathrm{T}$ cell mediated immune response in a manner that reduces the intracellular stability of the tuberculosis bacterium [28]. This fact is observed to be true for many other intracellular infection and so may be considered as a general phenomenon [29]. Extra cellular superoxide dismutase is shown to augment phagocytic killing of bacteria [30]. There is evidence in in-vivo studies that control of oxidative stress by supply of antioxidants is beneficial for prevention and treatment of tuberculosis [31]. In living human tuberculosis patients oxidative stress is also proved beyond any doubt [32]. The activities of antioxidant enzymes are observed to be comparatively less in blood samples in subjects suffering from active tuberculosis along with corroborative increase in concentration of protein carbonyl [33].

Therefore antioxidants if neutralize the phagosomal oxidants has the chance to augment active form of tuberculosis. In other hand if antioxidants are expected to modulate the immune response to combat intracellular infection then it may act as a preventive armor for tuberculosis. In the context of tuberculosis supplementation of antioxidants will play beneficial role or not needs a solution of the paradoxical evidences so far accumulated.

\section{SOLUTION OF THE PARADOX}

Clinical effect of vitamin $\mathrm{E}$ is not observed in recipients who consume less vitamin C containing diet [34]. It has been observed that vitamin $\mathrm{E}$ supplementation transiently 
increases the risk of active tuberculosis in heavy smokers if co-supplemented with vitamin C [35]. Similar conclusions are arrived in clinical cases of pneumonia [36]. Therefore vitamin $\mathrm{C}$ and vitamin $\mathrm{E}$ co-supplementation may be harmful for any infectious disease including tuberculosis. It is possible that vitamin $\mathrm{C}$ neutralizes tocopheryl radical that may have microbiocidal role.

Oxidative stress is a proved fact associated with tuberculosis $[31,32]$. Oxidative stress is a phenomenon that may cause immunosuppression [37]. Oxidative stress results into defective $T$ cell mediated immunity [38] which in turn may accelerate tuberculosis infection. Therefore antioxidant supplementation in tuberculosis patients along with recommended chemotherapy may help to combat the oxidative stress mediated defective cell mediated immunity. In the context of tuberculosis management, treatment of the cause of the disease is important since now it is a recognized fact that in the scenario of oxidative stress the management must address the cause of genesis of the primary disease [39]. However both endogenous and exogenous antioxidants are observed to be protective against antitubercular drug induced toxicity $[40,41]$. Therefore co administration of antioxidants and anti-tubercular drugs has the potential to serve benefit to tuberculosis patients for multiple causes. But blind supplementation of antioxidants with anti-tubercular drugs in tuberculosis patients may cause more harm than benefit. We believe that if oxidative stress develops in a particular case of tuberculosis appropriate antioxidant supplementation along with antitubercular therapy will accelerate the healing process. Therefore clinical trials in this direction are warranted to document objective data to formulate rational antioxidant combination therapy as an adjunct to antitubercular drug therapy in proved cases of tuberculosis.

\section{ACKNOWLEDGEMENTS}

DB acknowledges Department of Biotechnology, Govt. of India for financial assistance.

\section{REFERENCES}

[1] Villanueva, C. and Kross, R.D. (2012) Antioxidant induced stress. International Journal of Molecular Science, 13, 2091-2109. http://dx.doi.org/10.3390/ijms13022091

[2] Kinchen, J.M. and Ravichandran, K.S. (2008) Phagosome maturation: Going through the acid test. Nature Reviews Molecular Cell Biology, 9, 781-795. http://dx.doi.org/10.1038/nrm2515

[3] Miller, B.H., Fratti, R.A., Poschet, J.F., et al. (2004) Mycobacteria inhibit nitric oxide synthase recruitment to phagosomes during macrophage infection. Infection and Immunity, 72, 2872-2878. http://dx.doi.org/10.1128/IAI.72.5.2872-2878.2004
[4] Lee, P.P., Chan, K.W., Jiang, L., et al. (2008) Susceptibility to mycobacterial infections in children with $\mathrm{X}$ linked chronic granulomatous disease: A review of 17 patients living in a region endemic for tuberculosis. The Pediatric Infectious Disease Journal, 27, 224-230. http://dx.doi.org/10.1097/INF.0b013e31815b494c

[5] Botti, H., Batthyány, C., Trostchansky, A., et al. (2004) Peroxynitrite-mediated alpha-tocopherol oxidation in lowdensity lipoprotein: A mechanistic approach. Free Radical Biology and Medicine, 36, 152-162. http://dx.doi.org/10.1016/j.freeradbiomed.2003.10.006

[6] Maguire, J.J., Wilson, D.S. and Packer, L. (1989) Mitochondrial electron transport-linked tocopheroxyl radical reduction. Journal of Biological Chemistry, 264, 2146221465.

[7] Damiani, E., Astolfi, P., Carloni, P., Stipa, P. and Greci, L. (2008) Antioxidants: How they work. In: Valacchi, G. and Davis, P.A., Eds., Oxidants in Biology, Springer Science Buisness Media, New York, 251-266. http://dx.doi.org/10.1007/978-1-4020-8399-0_12

[8] Duracková, Z. (2008) Oxidants, antioxidants and oxidative stress. In: Gvozdjáková, A., Ed., Mitochondrial Medicine, Springer Science Business Media, New York, 1954. http://dx.doi.org/10.1007/978-1-4020-6714-3_2

[9] Liu, C., Russell, R.M. and Wang, X.D. (2004) Alphatocopherol and ascorbic acid decrease the production of beta-apo-carotenals and increase the formation of retinoids from beta-carotene in the lung tissues of cigarette smoke-exposed ferrets in vitro. Journal of Nutrition, 134, 426-430.

[10] Yeum, K.J., Aldini, G., Russell, R.M. and Krinsky, N.I. (2009) Carotenoids, Vol. 5, Birkhäuser Verlag, Basel, 235268.

[11] Vergne, I., Chua, J. and Deretic, V. (2003) Mycobacterium tuberculosis phagosome maturation arrest: Selective targeting of PI3P-dependent membrane trafficking. Traffic, 4, 600-606. http://dx.doi.org/10.1034/j.1600-0854.2003.00120.x

[12] Puri, R.V., Reddy, P.V. and Tyagi, A.K. (2013) Secreted acid phosphatase (SapM) of mycobacterium tuberculosis eIs indispensable for arresting phagosomal maturation and growth of the pathogen in guinea pig tissues. PLoS One, 8, e70514.

http://dx.doi.org/10.1371/journal.pone.0070514

[13] Luo, M., Fadeev, E.A. and Groves, J.T. (2005) Mycobactin-mediated iron acquisition within macrophages. Nature Chemical Biology, 1, 149-153. http://dx.doi.org/10.1038/nchembio717

[14] Banerjee, D., Bhattacharyya, R., Kaul, D. and Sharma, P. (2011) Diabetes and tuberculosis: Analysis of a paradox. Advance in Clinical Chemistry, 53, 139-153.

[15] Bhattacharyya, R. and Banerjee, D. (2011) Glycation of calmodulin binding domain of iNOS may increase the chance of occurrence of tuberculosis in chronic diabetic state. Bioinformation, 7, 324-327. http://dx.doi.org/10.6026/97320630007324

[16] Trivedi, A., Singh, N., Bhat, S.A., Gupta, P. and Kumar, A. (2012) Redox biology of tuberculosis pathogenesis. 
Advances in Microbial Physiology, 60, 263-324. http://dx.doi.org/10.1016/B978-0-12-398264-3.00004-8

[17] Braunstein, M., Espinosa, B.J., Chan, J., Belisle, J.T. and Jacobs Jr., W.R. (2003) SecA2 functions in the secretion of superoxide dismutase A and in the virulence of Mycobacterium tuberculosis. Molecular Microbiology, 48, 453464. http://dx.doi.org/10.1046/j.1365-2958.2003.03438.x

[18] Piddington, D.L., Fang, F.C., Laessig, T., Cooper, A.M., Orme, I.M. and Buchmeier, N.A. (2001) Cu, Zn superoxide dismutase of Mycobacterium tuberculosis contrib.utes to survival in activated macrophages that are generating an oxidative burst. Infection and Immunity, 69, 4980-4987.

http://dx.doi.org/10.1128/IAI.69.8.4980-4987.2001

[19] Sao Emani, C., Williams, M.J., Wiid, I.J., Hiten, N.F., Viljoen, A.J., Pietersen, R.D., van Helden, P.D. and Baker, B. (2013) Ergothioneine is a secreted antioxidant in Mycobacterium smegmatis. Antimicrobial Agents and Chemotherapy, 57, 3202-3207. http://dx.doi.org/10.1128/AAC.02572-12

[20] Gurumurthy, M., Rao, M., Mukherjee, T., Rao, S.P., Boshoff, H.I., Dick, T., Barry, C.E. 3rd and Manjunatha, U.H. (2013) A novel F(420)-dependent anti-oxidant mechanism protects Mycobacterium tuberculosis against oxidative stress and bactericidal agents. Molecular Microbiology, 87, 744-755. http://dx.doi.org/10.1111/mmi.12127

[21] Saikolappan, S., Das, K., Sasindran, S.J., Jagannath, C. and Dhandayuthapani, S. (2011) OsmC proteins of Mycobacterium tuberculosis and Mycobacterium smegmatis protect against organic hydroperoxide stress. Tuberculosis, 91, S119-S127. http://dx.doi.org/10.1016/j.tube.2011.10.021

[22] Jain, R., Dey, B., Khera, A., Srivastav, P., Gupta, U.D., Katoch, V.M., Ramanathan, V.D. and Tyagi, A.K. (2011) Over-expression of superoxide dismutase obliterates the protective effect of BCG against tuberculosis by modulating innate and adaptive immune responses. Vaccine, 29, 8118-8125. http://dx.doi.org/10.1016/j.vaccine.2011.08.029

[23] De Groote, M.A., Ochsner, U.A., Shiloh, M.U., et al. (1997) Periplasmic superoxide dismutase protects Salmonella from products of phagocyte NADPH-oxidase and nitric oxide synthase. Proceedings of the National Academy of Science of United States of America, 94, 13997-4001. http://dx.doi.org/10.1073/pnas.94.25.13997

[24] Frohner, I.E., Bourgeois, C., Yatsyk, K., Majer, O. and Kuchler, K. (2009) Candida albicans cell surface superoxide dismutases degrade host-derived reactive oxygen species to escape innate immune surveillance. Molecular Microbiology, 71, 240-252. http://dx.doi.org/10.1111/j.1365-2958.2008.06528.x

[25] Youseff, B.H., Holbrook, E.D., Smolnycki, K.A. and Rappleye, C.A. (2012) Extracellular superoxide dismutase protects Histoplasma yeast cells from host-derived oxidative stress. PLoS Pathogens, 8, e1002713. http://dx.doi.org/10.1371/journal.ppat.1002713

[26] Oberley-Deegan, R.E., Rebits, B.W., Weaver, M.R., et al. (2010) An oxidative environment promotes growth of Mycobacterium abscessus. Free Radical Biology and Me- dicine, 49, 1666-1673.

http://dx.doi.org/10.1016/j.freeradbiomed.2010.08.026

[27] Oberley-Deegan, R.E., Lee, Y.M., Morey, G.E., Cook, D.M., Chan, E.D. and Crapo, J.D. (2009) The antioxidant mimetic, MnTE-2-PyP, reduces intracellular growth of Mycobacterium abscessus. American Journal of Respiratory Cell and Molecular Biology, 41, 170-178. http://dx.doi.org/10.1165/rcmb.2008-01380C

[28] Guerra, C., Morris, D., Sipin, A., et al. (2011) Glutathione and adaptive immune responses against Mycobacterium tuberculosis infection in healthy and HIV infected individuals. PLoS One, 6, e28378. http://dx.doi.org/10.1371/journal.pone.0028378

[29] Morris, D., Khurasany, M., Nguyen, T., et al. (2013) Glutathione and infection. Biochimica et Biophysica Acta, 1830, 3329-3349. http://dx.doi.org/10.1016/j.bbagen.2012.10.012

[30] Manni, M.L., Tomai, L.P., Norris, C.A., et al. (2011) Extracellular superoxide dismutase in macrophages augments bacterial killing by promoting phagocytosis. The American Journal of Pathology, 178, 2752-2759. http://dx.doi.org/10.1016/j.ajpath.2011.02.007

[31] Palanisamy, G.S., Kirk, N.M., Ackart, D.F., et al. (2011) Evidence for oxidative stress and defective antioxidant response in guinea pigs with tuberculosis. PLoS One, 6, e26254. http://dx.doi.org/10.1371/journal.pone.0026254

[32] Dalvi, S.M., Patil, V.W., Ramraje, N.N., Phadtare, J.M. and Gujarathi, S.U. (2013) Nitric oxide, carbonyl protein, lipid peroxidation and correlation between antioxidant vitamins in different categories of pulmonary and extra pulmonary tuberculosis. The Malaysian Journal of Medical Sciences, 20, 21-30.

[33] Dalvi, S.M., Patil, V.W. and Ramraje, N.N. (2012) The roles of glutathione, glutathione peroxidase, glutathione reductase and the carbonyl protein in pulmonary and extra pulmonary tuberculosis. Journal of Clinical and Diagnostic Research, 6, 1462-1465.

[34] Hemilä, H. and Kaprio J. (2009) Modification of the effect of vitamin E supplementation on the mortality of male smokers by age and dietary vitamin C. American Journal of Epidemiology, 169, 946-953. http://dx.doi.org/10.1093/aje/kwn413

[35] Hemilä, H. and Kaprio, J. (2008) Vitamin E supplementation may transiently increase tuberculosis risk in males who smoke heavily and have high dietary vitamin C intake. The British Journal of Nutrition, 100, 896-902. http://dx.doi.org/10.1017/S0007114508923709

[36] Hemilä, H. and Kaprio, J. (2008) Vitamin E supplementation and pneumonia risk in males who initiated smoking at an early age: Effect modification by body weight and dietary vitamin C. Nutrition Journal, 7, 33. http://dx.doi.org/10.1186/1475-2891-7-33

[37] Zhang, Z.W., Wang, Q.H., Zhang, J.L., Li, S., Wang, X.L. and Xu, S.W. (2012) Effects of oxidative stress on immuno-suppression induced by selenium deficiency in chickens. Biological Trace Element Research, 149, 352361. http://dx.doi.org/10.1007/s12011-012-9439-0

[38] Efimova, O., Szankasi, P. and Kelley, T.W. (2011) Ncf1 
(p47phox) is essential for direct regulatory $\mathrm{T}$ cell mediated suppression of CD4+ effector T cells. PLoS One, $\mathbf{6}$, e16013. http://dx.doi.org/10.1371/journal.pone.0016013

[39] Naviaux, R.K. (2012) Oxidative shielding or oxidative stress? The Journal of Pharmacology and Experimental Therapeutics, 342, 608-618.

http://dx.doi.org/10.1124/jpet.112.192120

[40] Lian, Y., Zhao, J. and Xu, P. (2013) Protective effects of metallothionein on isoniazid and rifampicin-induced he- patotoxicity in mice. PLoS One, 8, e72058. http://dx.doi.org/10.1371/journal.pone.0072058

[41] Ergul, Y., Erkan, T., Uzun, H., Genc, H., Altug, T. and Erginoz, E. (2010) Effect of vitamin C on oxidative liver injury due to isoniazid in rats. Pediatrics International, 52, 69-74.

http://dx.doi.org/10.1111/j.1442-200X.2009.02891.x 